\title{
Analysis of phase change materials for regulating the thermal environment of greenhouses in different climatic conditions in Highland areas
}

\author{
Zhao Yan ${ }^{1}$, Liu Chaofu ${ }^{2, *}$, Li Yanqiong ${ }^{1}$, and Qiu Yan ${ }^{1}$ \\ ${ }^{1}$ Yunnan Agricultural University, Kunming 650204 China \\ ${ }^{2}$ Yunnan Institute of transportation planning and design, Kunming 650041 China
}

\begin{abstract}
Phase change materials have good peak-shaving and valley-filling effects, which are effective for improving the thermal environment of passive thermal storage buildings. In this paper, phase change materials were applied to a solar greenhouse in the plateau area, and the indoor temperature is measured and analyzed under different meteorological conditions. It was concluded that when phase change materials were applied in the central region of Yunnan, where the temperature difference between day and night was large, it had a significant improvement effect on the thermal environment inside the solar greenhouse. The average outdoor air temperature, the maximum outdoor temperature difference between day and night, and solar radiation were the main factors affecting the temperature in the greenhouse. By analyzing and evaluating the effect of using phase change materials in solar greenhouses under different outdoor climate conditions, the advantages and limitations of using phase change greenhouses in different areas of the plateau were discussed.
\end{abstract}

\section{Introduction}

The temperature variation in greenhouses plays a key role in the growth and development of indoor crops ${ }^{[1-2]}$. Different crops and different growth stages have different needs for indoor temperature. Generally speaking, the temperature inside the greenhouse should be controlled at $12^{\circ} \mathrm{C} \sim 34^{\circ} \mathrm{C}$ when growing crops. Traditional greenhouses have a simple structure and poor insulation performance, and the temperature inside the greenhouse is still greatly influenced by the outdoor temperature, which usually requires corresponding heating and insulation measures in winter and cooling measures in summer, with high energy consumption. Phase change greenhouse can use phase change material to absorb and release a large amount of latent heat through its phase change to realize energy transfer in time and space, store excess solar energy during the daytime, and release energy into the greenhouse at night when the temperature inside the greenhouse decreases, which can reduce the fluctuation of greenhouse temperature during the whole phase change cycle and create a more stable greenhouse microclimate environment with obvious energy-saving effect. Takeshi $\mathrm{K}$ and Tadahiko I et al ${ }^{[3]}$ conducted a comparison experiment between a laboratory room containing PCM wall panels and a normal gypsum board laboratory room and concluded that the thermal load of the laboratory room with PCM wall panels was smoothed, peak and valley reduction, and electricity consumption was decreased. Yang et al ${ }^{[4]}$ used disodium hydrogen phosphate dodecahydrate phase-change thermal storage wall panels to build a heliostat and found that the fluctuation of temperature in a typical sunny day was $4.2^{\circ} \mathrm{C}$ less than that of the control, and the average temperature in a typical cloudy day was $1.6^{\circ} \mathrm{C}$ higher than that of the control. Jiang ${ }^{[5]}$ et al. used decentralized encapsulation of mannite-based phase change energy storage material as a heat storage medium encapsulated in PVC-like plastic bags and placed in a homemade simple greenhouse and found that the maximum temperature decreased at noon and the minimum temperature increased in the early morning before sunrise by comparison with the control greenhouse. Naj jar $\mathrm{A}^{[6]}$ et al. simulated the thermal environment of a greenhouse containing phase change materials and the results obtained were consistent with the measured data, indicating that the use of phase change materials can reduce the indoor temperature difference and lower the maximum indoor temperature by about $5^{\circ} \mathrm{C}$ in summer. Many scholars have analyzed the microclimate inside greenhouses in the form of numerical models ${ }^{[7]} \sim{ }^{[9]}$ and the temperature change process of phase change walls ${ }^{[10] \sim[13]}$, all of which show that phase change materials have significant effects on reducing the temperature fluctuations inside greenhouses and regulating the microclimate inside greenhouses. In this paper, we analyzed the effect of phase change materials on regulating the thermal environment of greenhouses, explored the effect of using phase change greenhouses in different climatic conditions in Yunnan, and concluded the advantages and limitations of using

\footnotetext{
Corresponding author.E-mail address: 184209074@qq.com.
} 
phase change greenhouses in different regions of Yunnan, based on the highland climate characteristics of Yunnan with high solar radiation intensity during daytime and large temperature difference between day and night.

\section{Materials and Methods}

\subsection{Overview of the test site}

The test site was in Chuxiong Yi Autonomous Prefecture, Yunnan Province, located at $25^{\circ} 05^{\prime} \mathrm{N}, 101^{\circ} 53^{\prime} \mathrm{E}$, in the western part of the Yunnan-Guizhou Plateau and the main part of the Central Yunnan Plateau, at an altitude of $1773 \mathrm{~m}$ above sea level. Chuxiong Prefecture is a northern subtropical dry winter and wet summer monsoon climate zone, the temperature difference between the day and small annual difference; winter without severe cold, summer without heat, dry and wet seasons are distinct, rain and heat in the same season; sufficient sunshine, frost period is short. The average temperature is $17{ }^{\circ} \mathrm{C}$, the extreme low temperature (January) is $4^{\circ} \mathrm{C}$, the extreme high temperature (June) is $27^{\circ} \mathrm{C}$, and the average annual sunshine is 2450 hours in the state. The favorable geographical environment provides convenient conditions for the development of facility agriculture.

\subsection{Test greenhouse}

The greenhouse tested is a common small orchid growing greenhouse in Chuxiong, and the structure of the greenhouse is shown in Figure 1. The greenhouse is facing south, with a length and span of 4.7 and $3.1 \mathrm{~m}$ respectively, and a height of $3.3 \mathrm{~m}$. The north wall of the greenhouse is $120 \mathrm{~mm}$, the lower part of the enclosure is $1 \mathrm{~m}$ high, and the rest is ordinary glass, the top of the greenhouse is a double-glass roof. The phase change material is paraffin wax, with a phase change temperature of $25^{\circ} \mathrm{C}$ and latent heat of phase change of $220 \mathrm{~kJ} / \mathrm{kg}$. The phase change material was placed on the glass of the south side of the envelope in the form of adhesive fixation, and the area covered by the phase change material is $1700 \times 900(\mathrm{~mm})$. The encapsulation method of phase change material is shown in Figure 2.

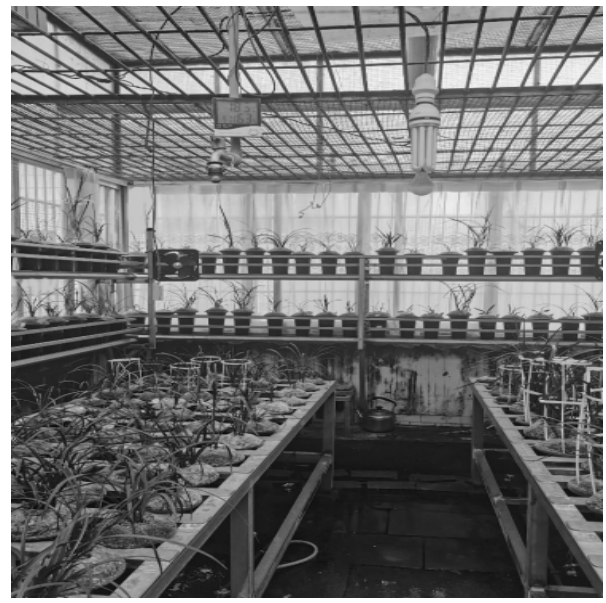

Fig.1. Greenhouse structure

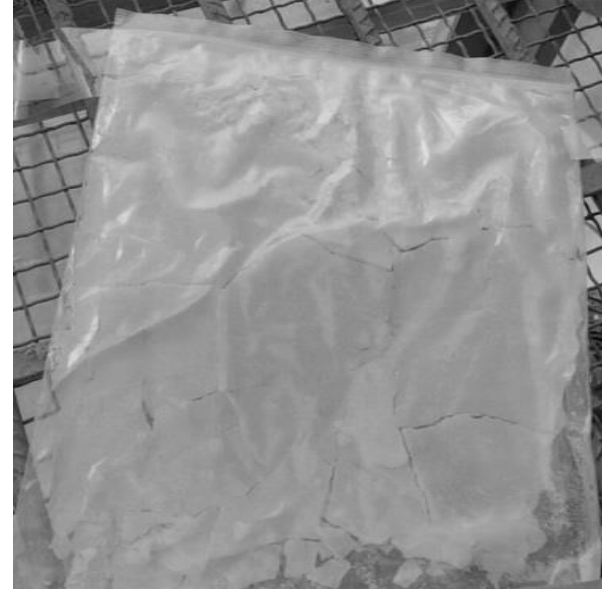

Fig.2. Packaging mode of PCM

\subsection{Placement of measurement points}

The air temperature in the greenhouse was measured during the experiment. The air temperature measurement points were divided into four heights, namely $0.5 \mathrm{~m}, 1.5 \mathrm{~m}$, $2.5 \mathrm{~m}$, and $3.2 \mathrm{~m}$; among them, three points were placed along the span direction at $0.8 \mathrm{~m}, 2.7 \mathrm{~m}$, and $3.9 \mathrm{~m}$ in the span direction for the $0.5 \mathrm{~m}, 1.5 \mathrm{~m}$ and $2.5 \mathrm{~m}$ height points; two points were placed along the span direction at $2.7 \mathrm{~m}$ and $3.9 \mathrm{~m}$ in the span direction for the $3.2 \mathrm{~m}$ height points. An automatic weather station was set up at $5 \mathrm{~m}$ from the west side of the greenhouse to collect wind direction and speed, outdoor temperature and humidity, and solar radiation values. The specific distribution points are shown in Figure 3.

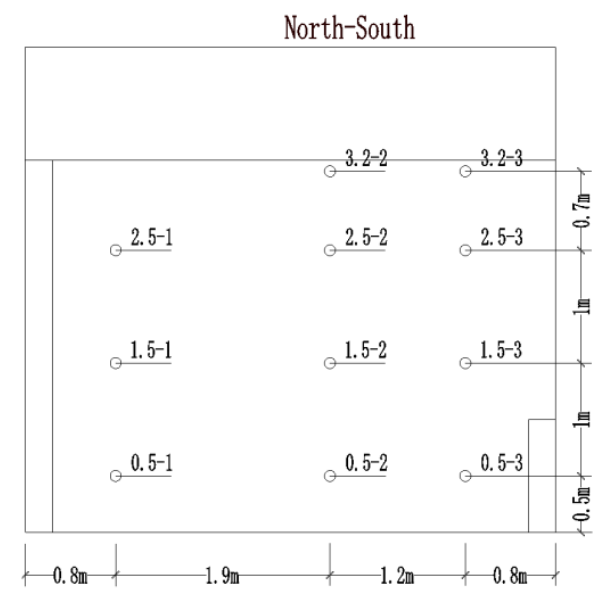

Fig.3. Sensors arrangement of greenhouse

\subsection{Testing Instruments}

Indoor and outdoor temperature were measured by German Testo temperature and humidity automatic recorder, the accuracy of the self-recording instrument are $\pm 0.5^{\circ} \mathrm{C}$, and the working environment temperature is $-20^{\circ} \mathrm{C} \sim 70^{\circ} \mathrm{C}$. The data were recorded every 10 minutes during the test, and downloaded and analyzed regularly. Outdoor wind speed and solar radiation were measured by Jinzhou Licheng automatic weather station, which has a temperature measurement accuracy of $\pm 0.1^{\circ} \mathrm{C}$ and a 
measurement range of $-50{ }^{\circ} \mathrm{C} \sim 100{ }^{\circ} \mathrm{C}$, wind speed accuracy of $0.1 \mathrm{~m} / \mathrm{s}$ and a measurement range of $0 \sim 75 \mathrm{~m} / \mathrm{s}$, and wind direction accuracy of $1^{\circ}$ and a measurement range of $0^{\circ} \sim 360^{\circ}$.

\section{Results and analysis}

The air temperature inside the greenhouse plays a key role in the growth and development of plants, so this paper takes the air temperature as a key index to evaluate the thermal environment of the greenhouse, and the spatial and temporal patterns of air temperature inside the greenhouse under different weather conditions during the test period were selected for analysis. Figures 4, 5, 6, and 7 plot the spatial and temporal distribution of air temperature inside the greenhouse from 12:00 a.m. to 12:00 p.m. on Feb.19, Feb.20, Feb.22, and Feb.23, 2021, respectively. Feb.19 and Feb.20, 2021, was cloudy, and the average outdoor air temperature was $16.43{ }^{\circ} \mathrm{C}$ and $16.46{ }^{\circ} \mathrm{C}$ respectively; Feb.22 and Feb. 23 was sunny, and the average outdoor air temperature was $18.53{ }^{\circ} \mathrm{C}$ and $18.58{ }^{\circ} \mathrm{C}$ respectively. No phase change material was placed in the greenhouse on Feb.19, which was used as the reference day. The phase change materials were placed in the greenhouse during the rest of the test period.

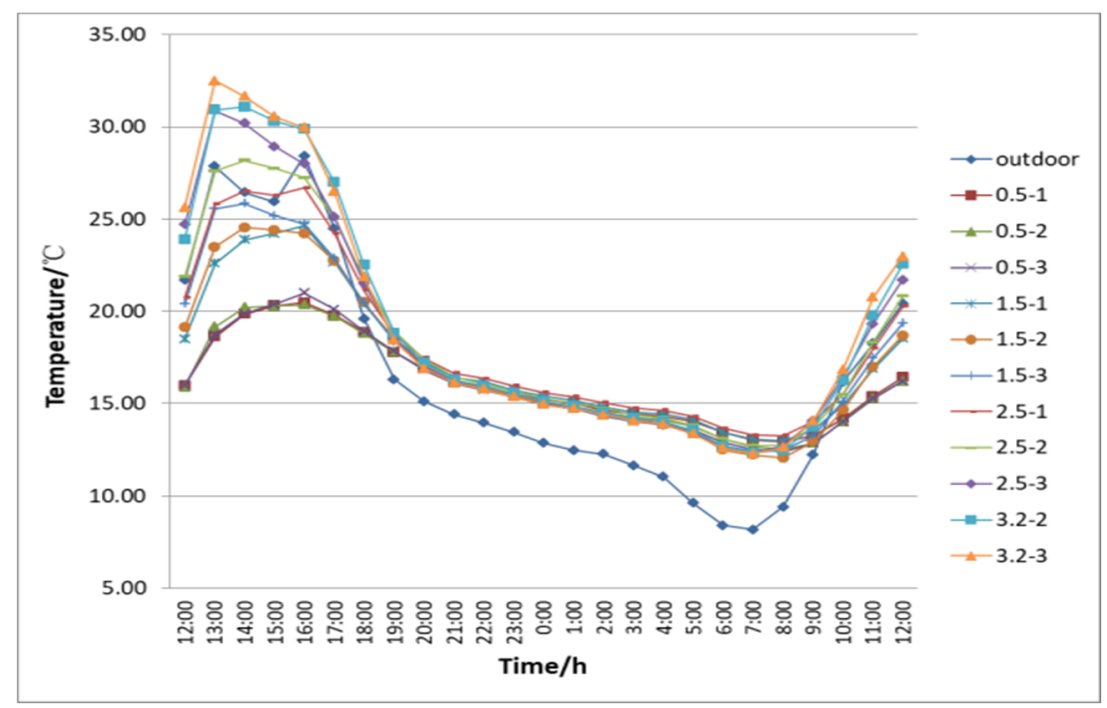

Fig.4. Temporal and spatial distribution of indoor and outdoor air temperature in the greenhouse on Feb. 19

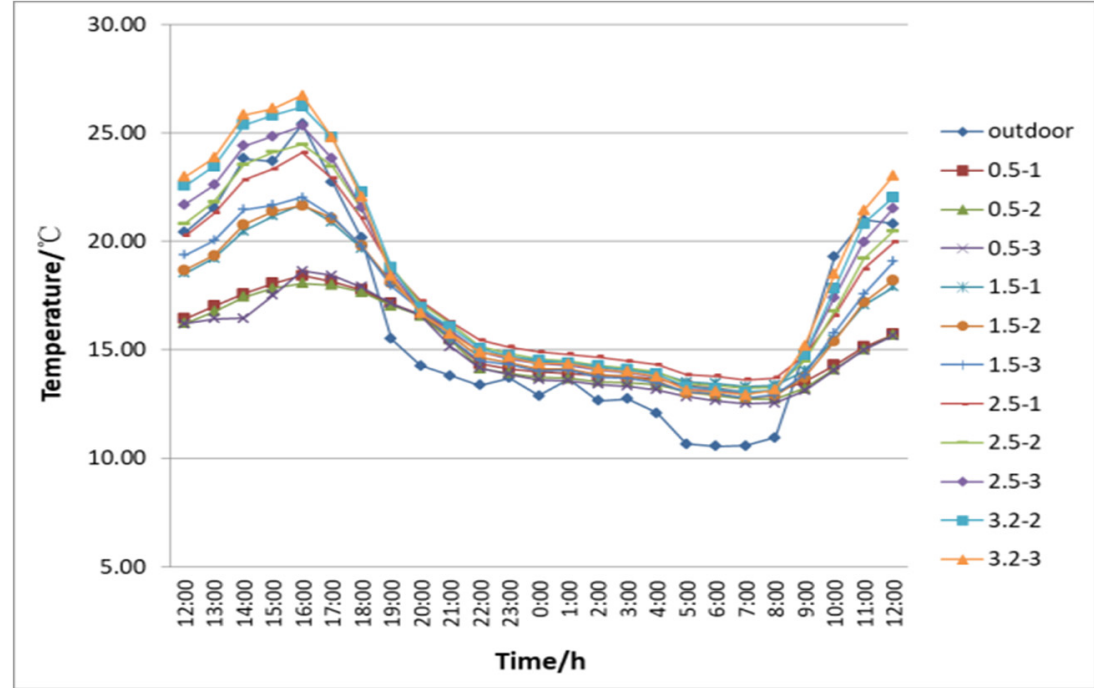

Fig.5. Temporal and spatial distribution of indoor and outdoor air temperature in the greenhouse on Feb. 20 


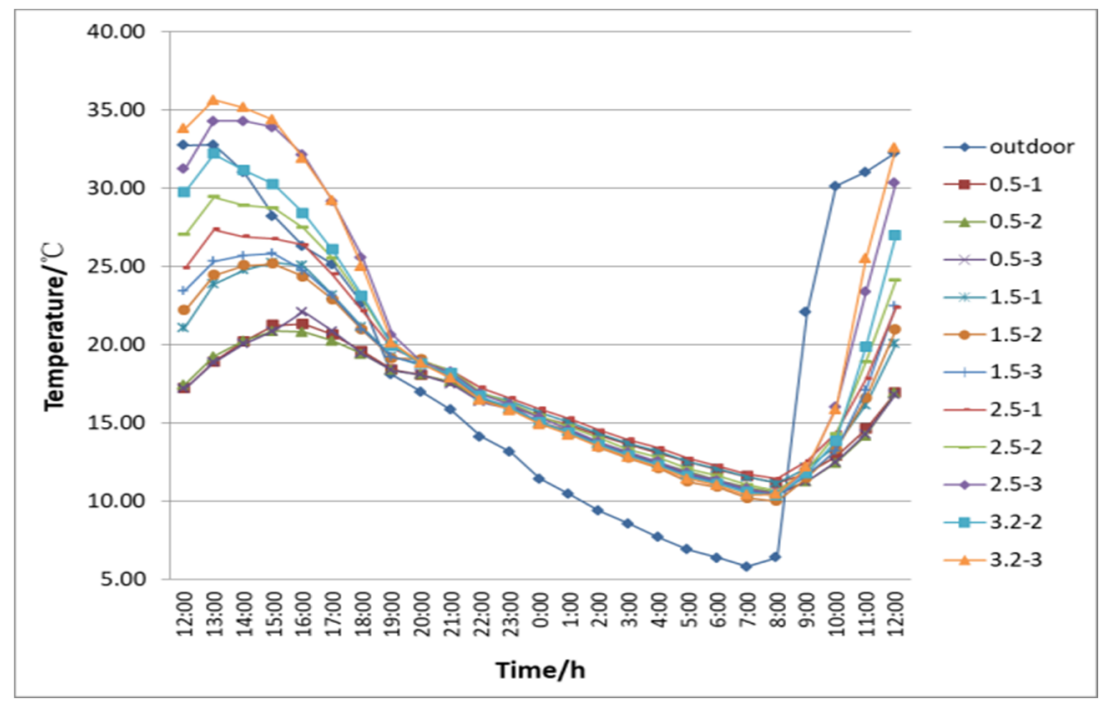

Fig.6. Temporal and spatial distribution of indoor and outdoor air temperature in the greenhouse on Feb. 22

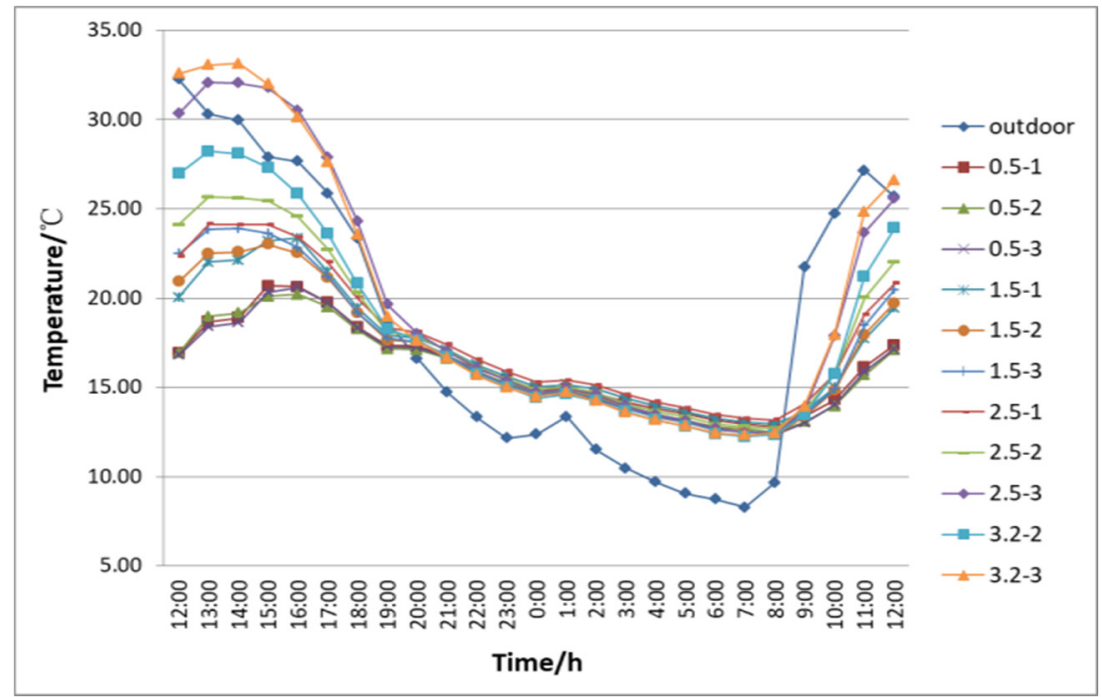

Fig.7. Temporal and spatial distribution of indoor and outdoor air temperature in the greenhouse on Feb. 23

As can be seen from the figure, the overall trend of air temperature change in the greenhouse under different weather conditions was generally similar, all rising and then falling during the day under the influence of solar radiation, and continuing to fall at night and tends to stabilize. In the daytime lighting stage, the temperature changed of the same height in the horizontal direction was flat. Under cloudy weather conditions, the maximum temperature difference between the upper and lower parts of the greenhouse was $14.9^{\circ} \mathrm{C}$ (Feb.19) when no phase change materials were placed and $10.3^{\circ} \mathrm{C}$ (Feb.20) when phase change materials were placed. The maximum temperature difference between the upper and lower parts of the greenhouse was $17.8^{\circ} \mathrm{C}$ (Feb.22) and $16.5^{\circ} \mathrm{C}$ (Feb.23), respectively, under sunny weather conditions. At night, the temperature difference between all measurement points was small, the maximum indoor temperature difference at night was $0.5^{\circ} \mathrm{C}$ under cloudy weather, and $0.6^{\circ} \mathrm{C}$ (Feb.22) and $0.7^{\circ} \mathrm{C}$ (Feb.23) under sunny weather, indicating that the spatial distribution of indoor temperature at night was uniform.

The effect of setting phase change materials on indoor air temperature was compared under different meteorological conditions. The outdoor air temperature peaked at $30.9^{\circ} \mathrm{C}$ at $13: 30$ on Feb.19 without setting phase change materials, and the lowest temperature was $8^{\circ} \mathrm{C}$ at $19: 40$, with a maximum temperature difference of $22.9^{\circ} \mathrm{C}$ in one test cycle; the highest indoor temperature was $34^{\circ} \mathrm{C}$, which was $3.1{ }^{\circ} \mathrm{C}$ higher than the highest outdoor air temperature. The lowest temperature was $11.9{ }^{\circ} \mathrm{C}, 3.9^{\circ} \mathrm{C}$ higher than the lowest outdoor temperature, and the maximum temperature difference within an indoor test cycle was $22.1^{\circ} \mathrm{C}, 0.8^{\circ} \mathrm{C}$ lower than the maximum outdoor air temperature difference. Due to the thermal storage properties of the envelope itself, there was a delay in the appearance of the maximum temperature at four measurement points indoors, which occurred from 16:10 to 16:20, and there was no significant delay in the appearance of the maximum temperature at the other seven measurement points compared with the outdoor temperature. The minimum temperature at all measurement points indoors occurs at a time similar to that outdoors, and the minimum temperature values at all measurement points were close 
to each other, ranging from $11.9^{\circ} \mathrm{C}$ to $12.9^{\circ} \mathrm{C}$. On the same cloudy day, the phase change material was placed on Feb.20, and the outdoor air temperature peaked at $27.2^{\circ} \mathrm{C}$ at $16: 20$, the lowest temperature appeared at $10.2^{\circ} \mathrm{C}$ at 8:00 am the next day, with a maximum temperature difference of $17^{\circ} \mathrm{C}$ in one test cycle; the highest indoor temperature was $27.2^{\circ} \mathrm{C}$, the same as the highest outdoor air temperature, and the lowest temperature was $12.5^{\circ} \mathrm{C}$, which was $2.3{ }^{\circ} \mathrm{C}$ higher than the minimum outdoor air temperature. The maximum temperature difference during the indoor test cycle was $14.7^{\circ} \mathrm{C}$, which was $2.3{ }^{\circ} \mathrm{C}$ lower than the maximum outdoor air temperature difference. The peak indoor and outdoor air temperatures appeared close to each other, with a difference of no more than 20 minutes, and the indoor air temperature minimum appeared earlier than the outdoor air temperature. Feb.22 was a sunny day, the maximum outdoor air temperature appeared at $13: 10,35.1{ }^{\circ} \mathrm{C}$, and the minimum daily temperature was $5.6{ }^{\circ} \mathrm{C}$, which appeared at 7:30 am the next day, with a maximum temperature difference of $29.5{ }^{\circ} \mathrm{C}$ within the test cycle; the maximum indoor temperature was $36.3^{\circ} \mathrm{C}, 1.2^{\circ} \mathrm{C}$ higher than the highest outdoor air temperature, the lowest temperature was $9.8^{\circ} \mathrm{C}, 4.2^{\circ} \mathrm{C}$ higher than the lowest outdoor temperature, and the maximum indoor temperature difference was $26.5^{\circ} \mathrm{C}, 3^{\circ} \mathrm{C}$ lower than the maximum outdoor air temperature difference. There was a delay in the appearance of the maximum temperature at the six indoor measurement points below $1.5 \mathrm{~m}$, which occurred at 15:20 16:40, and there was no significant delay in the appearance of the maximum temperature at the other measurement points. The minimum temperature at all indoor measurement points appeared at the same time, at 8:10 a.m. the next day, with a delay of 40 minutes from the appearance of the minimum outdoor temperature. The minimum indoor temperature was close, with a temperature difference of no more than $1.5^{\circ} \mathrm{C}$ between measurement points. Feb.23 was a sunny day, with a maximum outdoor air temperature of $35.1^{\circ} \mathrm{C}$, which appeared at 12:20., and a daily minimum temperature of $8.2^{\circ} \mathrm{C}$, which appeared at 7:30 a.m. the next day. The maximum temperature difference was $26.9^{\circ} \mathrm{C}$; the maximum indoor temperature was $33.8^{\circ} \mathrm{C}$, $1.3^{\circ} \mathrm{C}$ lower than the maximum outdoor air temperature, the minimum temperature was $12^{\circ} \mathrm{C}, 3.8^{\circ} \mathrm{C}$ higher than the minimum outdoor temperature, and the maximum indoor temperature difference was $21.8^{\circ} \mathrm{C}, 5.1^{\circ} \mathrm{C}$ lower than the maximum outdoor air temperature difference. The appearance of the maximum temperature at all indoor measurement points was delayed to varying degrees, with a delay time of 30 minutes to 4 hours. The minimum temperature of all indoor measurement points appeared at a similar time, around 8:10 a.m. the next day, with a delay of 40 minutes from the appearance of the minimum outdoor temperature. The minimum indoor temperature was close, with a temperature difference of no more than $1{ }^{\circ} \mathrm{C}$ between measurement points.

By comparing the changing trend of indoor air temperature values in four days, it can be seen that the maximum temperature difference between indoor and outdoor air temperature was similar when no phase change materials were placed, which was only $0.8^{\circ} \mathrm{C}$, and the temperature change pattern of most indoor measurement points was similar to that of outdoor air temperature without obvious delay. After placing the phase change material, the maximum temperature difference between indoor and outdoor air temperature still decreased to $2.3^{\circ} \mathrm{C}$ when the average outdoor air temperature on a cloudy day was close to that when the phase change material was not installed. The maximum temperature difference values of indoor and outdoor air temperature were $3^{\circ} \mathrm{C}$ and $5.1^{\circ} \mathrm{C}$ on sunny days.

\section{Conclusions}

Through the measurement of the air temperature inside and outside a greenhouse in central Yunnan, and comparing the changes of indoor air temperature under different meteorological conditions before and after setting phase change materials respectively, it can be found that:

The phase change materials can effectively reduce the maximum air temperature inside the greenhouse by absorbing heat during the day, and exotherm at night to increase the air temperature inside the greenhouse and create a reasonable temperature range for the growth of plants. Comparing the maximum temperature values in the greenhouse before and after setting phase change materials, it can be found that with similar average outdoor temperatures $\left(16.43{ }^{\circ} \mathrm{C}\right.$ and $16.46{ }^{\circ} \mathrm{C}$, respectively), the maximum indoor temperature was $34^{\circ} \mathrm{C}$ when no phase change materials were placed, which was $3.1^{\circ} \mathrm{C}$ higher than the maximum outdoor temperature, and the indoor and outdoor temperatures at night were $11.9^{\circ} \mathrm{C}$ and $8^{\circ} \mathrm{C}$, respectively; after setting phase change materials, the maximum indoor temperature was the same as the maximum outdoor temperature, $27.2^{\circ} \mathrm{C}$. The maximum indoor and outdoor temperatures were $12.5^{\circ} \mathrm{C}$ and $10.2^{\circ} \mathrm{C}$ respectively at night. On the other hand, the higher the average outdoor temperature, the more pronounced the delayed effect of the phase change material.

Phase change materials can reduce temperature fluctuations in the greenhouse. The higher the average outdoor temperature, the more obvious the effect of phase change materials on the regulation of temperature inside the greenhouse. When the phase change materials were not set, the difference between the maximum indoor and outdoor diurnal temperature was $0.8{ }^{\circ} \mathrm{C}$ in one test cycle. After setting the phase change materials, the maximum indoor diurnal temperature difference was $2.3{ }^{\circ} \mathrm{C}, 3{ }^{\circ} \mathrm{C}$, and $5.1{ }^{\circ} \mathrm{C}$ lower than the maximum outdoor diurnal temperature difference when the average outdoor air temperature was $16.46{ }^{\circ} \mathrm{C}, 18.53{ }^{\circ} \mathrm{C}$, and $18.58{ }^{\circ} \mathrm{C}$, respectively.

With similar average outdoor temperatures on Feb.22 and Feb.23 (18.53 ${ }^{\circ} \mathrm{C}$ and $18.58{ }^{\circ} \mathrm{C}$, respectively), the maximum indoor-outdoor temperature difference value 
on Feb.23 was $2.1{ }^{\circ} \mathrm{C}$ higher than that on Feb.22, because the outdoor solar radiation was stronger on Feb.23, and the temperature of the wall surface of the envelope structure increased, so the phase change material could better play the role of cutting the peak and filling the valley to regulate the room temperature.

The large outdoor temperature difference between day and night in the highland area also has a greater impact on the heat storage performance of the phase change materials. The effect of phase change materials in greenhouses in dry hot valleys, mild regions, and hot summer and cold winter regions can be further explored by utilizing simulations and combining outdoor meteorological parameters in different regions of Yunnan to provide references for the promotion of phase change greenhouses.

\section{Acknowledgments}

The study was supported by the "Research Fund Project of Yunnan Provincial Department of Education" (Grant no. 2020J0272).

\section{References}

1. Yu S. M, Liu Q. M. (1999) Agroclimatology during frost [M]. Beijing: Meteorological Press:182 -187.

2. Liu J, Liu ZP, Su H. (2016) Effect of temperature changes inside the greenhouse on crop growth[J]. Modern Agriculture. (14)

3. Takeshi K, Tadahiko I. (2001) Research on the storage of PCM wallboard.Ladahiko Tbamoto[D]. Tsubota Yuuji, No.540: 23-29.

4. YANG X L, WANG H L, et al. (2014) Performance of Phase Change Thermal Storage Wallboard of Disodium Hydrogen Phosphate Dodecahydrate in Solar Greenhouse [ J ] . Journal of Shanghai Jiaotong University(Agricultural Science) Vol . 32 No.4 Aug.
5. Jiang Z P, Tie S N. (2016) Property and Heat Storage Performances of Glauber's Salt-based Phase Change Materials for Solar Greenhouse in Qinghai-Tibet plateau[J]. Transactions of the Chinese Society of Agricultural Engineering (Transactions of the CSAE), 32(20): 209-216.

6. Naj jar A, Hason A. (2008)Modeling of the greenhouse with PCM energy storage[J]. Energy Conversion and Management, 49(11), 33: 38-42.

7. WANG T. (2020) Experimental and Numerical Study on Thermal Environmental Controlling in Solar Greenhouse with the Active-passive Phase Change Thermal Storage Wall [D] .Gansu: Lanzhou Jiaotong University.

8. Zhao J L. (2014) Research on Indoor Thermal Environment of Greenhouse in Cold Region.Heilongjiang [ D ] :Harbin Institute of Technology.

9. HU Q K. (2016) Application of phase change materials in building energy conservation and simulation experiment [D]:Huainan: Anhui University of Science And Technology.

10. HU X F, XIAO D. (2009) Research on the properties of the phase change power storage building material temperature response through ANSYS [J]. Materials review, 23 (22):83-86.

11. SHI C. (2015) Research on the application of phase change material RT28 in the building wall [D] . Hefei: Anhui Jianzhu University.

12. ZHANG L M, ZOU Z R, LU G D, et al. (2008) The preparation of compound phase change material of greenhouse wall and analyzed by ANSYS [J] . Journal of agricultural mechanization research, 30 (4) :158- 170.

13. SUN X, ZOU Y. (2010) Simulation of temperature changing process of phase change wall material with computer $[\mathrm{J}]$. Building energy conservation, 38 (9) :58-60, 65. 